This item was submitted to Loughborough's Research Repository by the author.

Items in Figshare are protected by copyright, with all rights reserved, unless otherwise indicated.

\title{
Do leading indicators forecast U.S. recessions? A nonlinear re-evaluation using historical data
}

PLEASE CITE THE PUBLISHED VERSION

https://doi.org/10.1111/infi.12111

\section{PUBLISHER}

(c) Wiley

\section{VERSION}

AM (Accepted Manuscript)

\section{PUBLISHER STATEMENT}

This is the peer reviewed version of the following article: PLAKANDARAS, V. ... et al, 2017. Do leading indicators forecast U.S. recessions? A nonlinear re-evaluation using historical data. International Finance, 20 (3), pp. 289-316., which has been published in final form at https://doi.org/10.1111/infi.12111. This article may be used for non-commercial purposes in accordance with Wiley Terms and Conditions for Use of SelfArchived Versions.

\section{LICENCE}

CC BY-NC-ND 4.0

\section{REPOSITORY RECORD}

Plakandaras, Vasilios, Juncal Cunado, Rangan Gupta, and Mark Wohar. 2019. "Do Leading Indicators Forecast U.S. Recessions? A Nonlinear Re-evaluation Using Historical Data". figshare. https://hdl.handle.net/2134/27917. 


\title{
Do Leading Indicators Forecast U.S. Recessions? A Nonlinear Re-evaluation Using Historical Data*
}

\author{
Vasilios Plakandaras ${ }^{*}$, Juncal Cunado ${ }^{* *}$, Rangan Gupta ${ }^{* * *}$ and Mark E. Wohar ${ }^{* * *+}$ \\ * Department of Economics, Democritus University of Thrace, Greece \\ Email: vplakand@econ.duth.gr \\ ** Department of Economics, University of Navarra, Spain. \\ Email: jcunado@unav.es \\ *** Department of Economics, University of Pretoria, South Africa. \\ Email: rangan.gupta@up.ac.za \\ ${ }^{* * * *}$ College of Business Administration, University of Nebraska at Omaha USA, and \\ School of Business and Economics, Loughborough University, UK. \\ Email: mwohar@unomaha.edu
}

\begin{abstract}
This paper analyses to what extent a selection of leading indicators is able to forecast U.S. recessions, by means of both dynamic probit models and Support Vector Machine (SVM) models, using monthly data from January 1871 to June 2016. The results suggest that the probit models predict U.S. recession periods more accurately than SVM models up to six months ahead, while the SVM models are more accurate over longer horizons. Furthermore, SVM models appear to distinguish between recessions and tranquil periods better than probit models do. Finally, the most accurate forecasting models are those that include oil, stock returns and the term spread as leading indicators.
\end{abstract}

Keywords: Dynamic Probit Models, Support Vector Machines, U.S. Recessions.

JEL Codes: C53, E32, E37.

\footnotetext{
* We would like to thank two anonymous referees for many helpful comments. However, any remaining errors are solely ours.

${ }^{+}$Corresponding author.
} 


\section{Introduction}

In the wake of the Great Recession, considered by the International Monetary Fund the worst global recession since World War II (IMF, World Economic Outlook, April 2009), the usefulness of economic models in forecasting recessions has been questioned (Gadea and Perez-Quiros, 2015). By way of background to the recent increase in interest in this topic, a large body of literature has tried to find leading indicators of U.S. economic activity since the late 1980s (Harvey, 1988, 1989; Stock and Watson, 1989; Estrella and Hardouvelis, 1991; Estrella and Mishkin, 1998; Hamilton and Kim, 2002; Giacomi and Rossi, 2006; Berge and Jordá, 2011; Berge, 2015; Levanon et al., 2015; Liu and Moench, 2016). Despite the great volume of papers on this topic, accurately predicting business-cycle turning points is still a pertinent research topic, and increasingly so since the largely unpredicted Great Recession.

In this context, the objective of this paper is to determine to what extent a selection of leading indicators is able to forecast U.S. recessions. The contributions of the paper are threefold. The secondfirst contribution of the paper is the use of a long period of data, 1871:01-2016:06, which includes very distinct episodes in the U.S. economy. Although many economic variables (e.g. the yield curve) provide useful information about future states of the economy, the relationship between these indicators and the state of the economy has declined since the 1980s (Gertler and Lown, 1999; Mody and Taylor, 2003; Rossi and Sekhposyan, 2011). Moreover, Stock and Watson (2003) and Chauvet and Potter (2005) find evidence of structural breaks in the relationship between the yield curve and economic activity. The existence of these changes justifies the use of a long time period of data to analyse the forecasting ability of different methods.

FirstSecond, the paper uses an ample selection of leading indicators and analyses the forecasting ability of each of them. The academic literature has proposed a wide variety of variables to predict U.S. recessions. The slope of the yield curve-that is, the (log) difference between long-term and short-term interest rates-has been found to be one of the most informative leading indicators for predicting U.S. recessions (Harvey, 1988; Bernanke and Blinder, 1992; Dueker, 1997; Hamilton and Kim, 2002; 
Stock and Watson, 2003; Ang et al., 2006; Rudebusch and Williams, 2009; Liu and Moench, 2016). A flat curve indicates weak growth and, conversely, a steep curve will be followed by stronger growth. Other variables that have been considered informative are stock prices (Estrella and Mishkin, 1998; Hamilton, 2011; Killian and Vigfusson, 2013), the index of leading economic indicators (Stock and Watson, 1989; Berge and Jordá, 2011), credit market activity (Levanon et al., 2015), and financial intermediary leverage indicators (Liu and Moench, 2016). Hamilton (2011), Engemann et al. (2010) and Killian and Vigfusson (2013) also find that oil prices have considerable predictive power for U.S. recessions. In order to account for monetary policy, the literature has also included the short-term interest rate (Estrella and Hardouvelis, 1991) and various monetary aggregates (Hamilton and Kim, 2002) as explanatory variables.

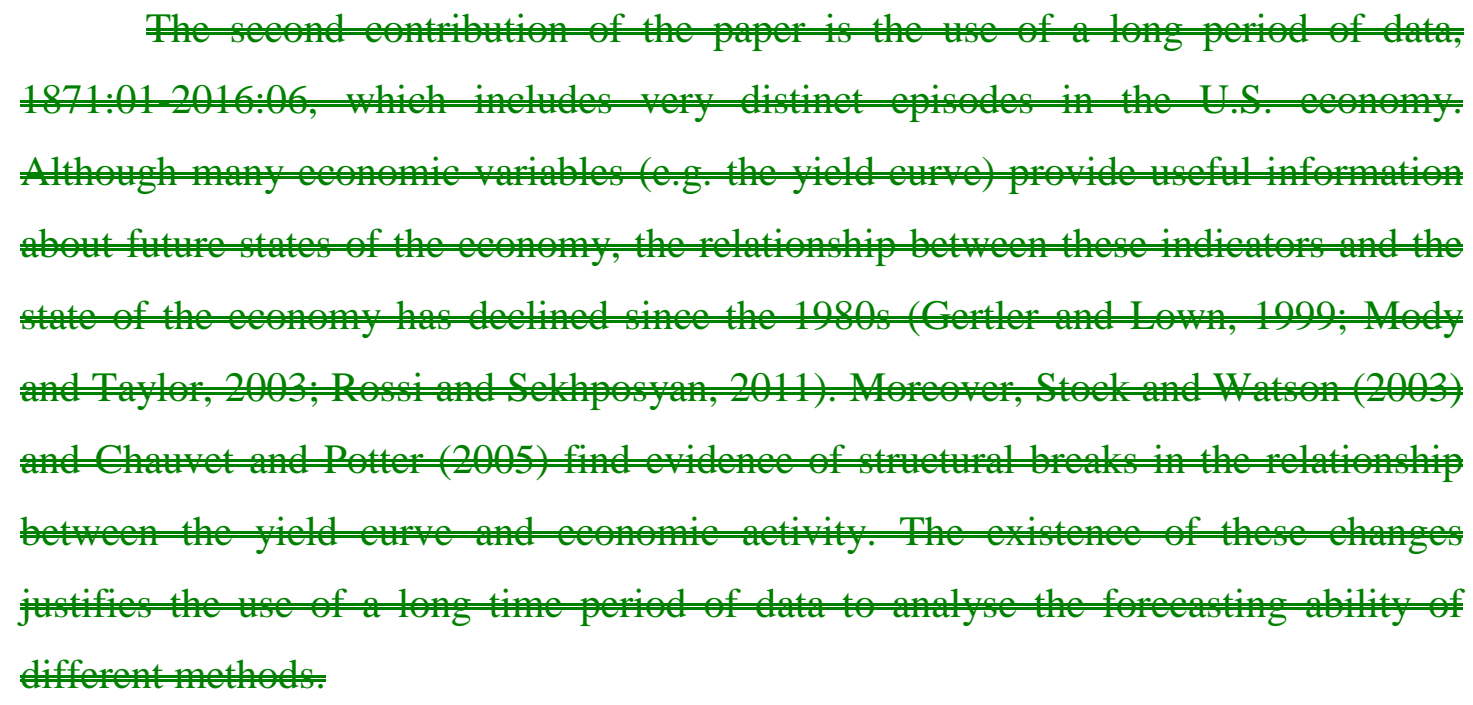

The third contribution of this paper is the use of both linear dynamic probit and nonlinear Support Vector Machines (SVM) models to predict U.S. recessions. As in most previous studies (Estrella and Mishkin, 1998; Dueker, 2005; Kauppi and Saikkonen, 2008; Berge, 2015; Liu and Moench, 2016) we use probit models based on the business cycle chronology proposed by the National Bureau of Economic Research (NBER) to define recessions. Although SVM models have seldom been used to predict recessions, among the few papers using this methodology, Gogas et al. (2015) applied the SVM model to analyse the ability of the yield curve to forecast U.S. output fluctuations around its long-run trend, using quarterly data for the period 1976:Q3-2011:Q4. Their results show that the SVM methodology outperformed 
classic econometric models (probit models) on overall forecast accuracy. In order to evaluate the accuracy of the predictions, the paper analyses both in-sample and outof-sample Quadratic Probability Scores (QPS) (Diebold and Rudebusch, 1989) for each of the models.

The remainder of the paper is structured as follows. Section 2 describes the data and discusses the methodology used in the paper. Section 3 shows the empirical analysis. Section 4 summarises the main findings.

\section{Data and Methodology}

\section{$2.1 \quad$ The Data}

We compiled a dataset of monthly observations spanning the period January 1871 to June 2016, which covers most of the historical information available on U.S. recessions. ${ }^{1}$ The dataset consists of the S\&P500 index, zero-coupon Treasury bills with maturities of 3 months and 10 years, and West Texas Intermediate (WTI) oil prices. The stock price and the long-term interest rate data are obtained from the website of Professor Robert J. Shiller. ${ }^{2}$ The CPI-U (Consumer Price Index All Urban Consumers), published by the U.S. Bureau of Labor Statistics, begins in 1913; for the years prior, we splice it with the CPI Warren and Pearson's price index by multiplying it with the ratio of the indexes for January 1913. The CPI data, also obtained from Professor Robert J. Shiller's website was used to generate real prices from the nominal stock and oil prices. The WTI oil price data are obtained from the Global Financial Database, while the short-term interest rate data are obtained from the website of Professor Amit Goyal ${ }^{3}$ through 2015:12, and thereafter from the Federal Reserve Bank of St. Louis. Note that we use both nominal and real stock and oil prices in our analysis, based on the suggestions of Stock and Watson (2003). Moreover, we decompose the yield curve into an expected short-term interest rate and a term premium component, following Hamilton and Kim (2000):

\footnotetext{
${ }^{1}$ Data on U.S. recessions is available at http://www.nber.org/cycles.html, and starts from December 1854.

${ }^{2}$ http://www.econ.yale.edu/ shiller/data.htm

${ }^{3}$ http://www.hec.unil.ch/agoyal/
} 


$$
i_{t}^{n}=\frac{1}{n} \sum_{j=0}^{n-1} E_{t} i_{t+j}^{1}+T P_{t}
$$

and equivalently

$$
\begin{gathered}
i_{t}^{n}-i_{t}^{1}=\left(\frac{1}{n} \sum_{j=0}^{n-1} E_{t} i_{t+j}^{1}-i_{t}^{1}\right)+T P_{t} \\
\text { where } T P_{t}=i_{t}^{n}-\frac{1}{n} \sum_{j=0}^{n-1} E_{t} i_{t+j}^{1}-i_{t}^{1}
\end{gathered}
$$

where $i_{t}^{n}$ denotes the long-term interest rate, $i_{t}^{1}$ the one-period short-term interest rate, $n$ the maturity of the long-term interest rate, $\left(\frac{1}{n} \sum_{j=0}^{n-1} E_{t} i_{t+j}^{1}-i_{t}^{1}\right)$ the future expected short-term interest rate at $t+j$ periods ahead, and $T P_{t}$ the term premium. Equation (2) can be estimated using an instrumental variable regression with $i_{t}^{n}$ and $i_{t}^{1}$ as instruments. In order to avoid transferring information on the dataset kept for out-ofsample forecasting, the estimations of equations (1) and (2) are made recursively each $\underline{\text { time, }}$ according to the observation to be forecasted.

In Figure 1, we depict the term spread and the decomposed expected shortterm interest rate and the term premium components. As we observe from Figure 1, the term spread exhibits a declining trend during the period 1925-1975. After 1975, the fluctuation of the term spread is higher, with the term premium reaching a significant positive percentage as a result of the high inflation rate during theat period. In other words, investors demanded greater compensation in order to hold Treasury Bills of longer maturity. Interestingly, during the Volcker administration, the inflation-targeted policies of the Federal Reserve pushed the term premium towards

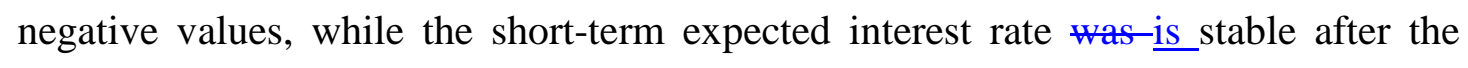
2008 financial crisis, at around 4\%. The divergence of the two-term spread components can be attributed to a 'flight-in-quality' phenomenon that is common during periods of recession; $\div$ investors prefer choose to invest their capital in government bonds (which are unlikely to default;) rather than to deploy them in-the open market. Thus, they push the short-term interest rate up, while they are indifferent to a positive term premium. Unit root tests and data transformations are reported ien the Appendix. 


\subsection{Methodology}

\subsubsection{Support Vector Machines}

Support Vector Machines is a supervised machine learning methodology used for data classification. The basic concept of an SVM is to select a small number of data points from a dataset, called Support Vectors (SV), defining a linear boundary separating the data points into classes. In what follows we describe briefly the mathematical derivations of the SVM theory.

We consider a dataset (vectors) $\mathrm{x}_{i} \in R^{2}(i=1,2, \ldots, n)$ belonging to two classes (targets ${ }^{4}$ ) $y_{i} \in\{-1,+1\}$. If the two classes are linearly separable, we define a boundary as:

$$
\mathrm{f}\left(\mathbf{x}_{i}\right)=\mathbf{w}^{\mathrm{T}} \mathbf{x}_{i}-b=0, \quad \mathrm{y}_{i} \mathrm{f}\left(\mathbf{x}_{i}\right)>0 \forall i
$$

where $\mathbf{w}$ is the weight vector and $b$ is the bias.

This optimal hyperplane is defined as the decision boundary that classifies each data vector with the maximum accuracyto the correct class_ and has the maximum distance from each class. This distance is often called a "margin”. In Figure 2 , the SVs are represented with a pronounced contour, the margin lines (defining the distance of the hyperplane from each class) are represented by solid lines and the hyperplane is represented by a dotted line.

In order to allow for a predefined level of error tolerance in the training procedure, Cortes and Vapnik (1995) introduce non-negative slack variables, $\xi_{i} \geq$ $0, \forall i$, and a parameter, $C$, describing the desired tolerance to classification errors. The solution to the problem of identifying the optimal hyperplane can be dealt with through the Lagrange relaxation procedure of the following equation:

$$
\min _{\mathbf{w}, b, \boldsymbol{\xi}} \max _{\mathbf{a} \boldsymbol{\mu}}\left\{\frac{1}{2}\|\mathbf{w}\|^{2}+C \sum_{i=1}^{N} \xi_{i}-\sum_{j=1}^{\mathrm{N}} a_{j}\left[y_{j}\left(\mathbf{w}^{\mathrm{T}} \mathbf{x}_{j}-b\right)-1+\xi_{j}\right]-\sum_{k=1}^{N} \mu_{k} \xi_{k}\right\}
$$

where $\xi_{i}$ measures the distance of vector $\mathrm{x}_{\mathrm{i}}$ from the hyperplane when classified erroneously, and $a 1, \ldots$, an are the non-negative Lagrange multipliers.

The hyperplane is then defined as:

${ }^{4}$ In the SVM jargon. 


$$
\begin{gathered}
\widehat{\mathbf{w}}=\sum_{i=1}^{N} a_{i} y_{i} \mathbf{x}_{i} \\
\widehat{\mathrm{b}}=\widehat{\mathbf{w}}^{\mathrm{T}} \mathbf{x}_{i}-y_{i}, i \in V
\end{gathered}
$$

where $V=\left\{i: 0<y_{i}<C\right\}$ is the set of support vector indices.

When the two-class dataset cannot be separated by a linear separator, the SVM is paired with kernel methods. The concept is quite simple: the dataset is projected through a kernel function into a richer space of higher dimensionality (called a feature space), where the dataset is linearly separable. In Figure 3, we depict a dataset of two classes that are not linearly separable in the initial dimensional space (left graph). After projection onto a higher dimensional space (right graph), the linear separation is feasible.

The solution to the dual problem with the projection of equation (6) now transforms to:

$$
\max _{\mathbf{a}}=\sum_{i=1}^{N} a_{i}-\frac{1}{2} \sum_{j=1}^{N} \sum_{k=1}^{N} a_{j} a_{k} y_{j} y_{k} \mathrm{~K}\left(\mathbf{x}_{j}, \mathbf{x}_{k}\right)
$$

under the constraints $\sum_{i=1}^{N} a_{i} y_{i}=0$ and $0 \leq a_{i} \leq C, \forall i$, where $\mathrm{K}\left(\mathbf{x}_{j}, \mathbf{x}_{k}\right)$ is the kernel function.

In our models, we examine two kernels: the linear kernel and the radial basis function $(\mathrm{RBF}) .^{5}$ The linear kernel detects the separating hyperplane in the original dimensional space of the dataset, while the RBF projects the initial dataset onto a higher dimensional space. The mathematical representation of each kernel is:

Linear

$\mathrm{RBF}$

$$
\begin{gathered}
K_{1}\left(\boldsymbol{x}_{1}, \boldsymbol{x}_{2}\right)=\boldsymbol{x}_{1}^{T} \boldsymbol{x}_{2} \\
K_{2}\left(\boldsymbol{x}_{1}, \boldsymbol{x}_{2}\right)=e^{-\gamma\left\|\boldsymbol{x}_{1}-\boldsymbol{x}_{2}\right\|^{2}}
\end{gathered}
$$

Platt (2000) proposes a parametric method for mapping the binary output of equation (3) to class probabilities. Fitting a sigmoid function on the posterior of $P(y=1 \mid f)$, we compute the posterior probability as:

$$
P(y=1 \mid f)=\frac{1}{1+\exp (A f+B)}
$$

\footnotetext{
${ }^{5}$ Our implementation of SVR models is based on LIBSVM (Chang and Lin, 2011). The software is available at http://www.csie.ntu.edu.tw/ cjlin/libsvm/.
} 
where $A$ and $B$ are parameters to be computed through a minimisation process. Bearing in mind that the targets follow $y_{i} \in\{-1,+1\}$, we assume that the target probabilities follow $k_{i}=y_{i}+1 / 2$. Thus, finding parameters $A$ and $B$ that fit the sigmoid function to the output of equation (4) is the equivalent of minimising the negative log-likelihood of

$$
\min \left(-\sum_{i} k_{i} \log \left(p_{i}\right)+\left(1-k_{i}\right) \log \left(1-p_{i}\right)\right)
$$

where

$$
p_{i}=\frac{1}{1+\exp (A f+B)}
$$

An SVM model coupled with a probabilistic mapping of the binary output can be seen as a nonlinear version of popular econometric binary classifiers, such as probit and logit models. The use of a kernel function in mapping the data in higher dimensional spaces does not allow for an analytical form; thus, it is not possible to make inferences about the effect of each regressor on the final result of the forecast. In other words, SVM models work as 'black-boxes', where only inputs and outputs are observable, much like neural networks or Markov-switching models. As with SVMs, in Markov-switching models the regime transition is defined endogenously, and we can only observe the transition probabilities or the coefficients in each regime. Nevertheless, by virtue of its nonlinear nature, the SVM methodology is capable of capturing nonlinear phenomena, which often exist in the very mechanism that generate the data.

\subsubsection{Dynamic Probit Models}

In this study, we exploit binary response models that predict recessions as a directly observable binary time-series response. We denote the binary state variable as $s_{t}$, where:

$$
s_{t}=\left\{\begin{array}{l}
1, \text { the economy is in recession at time } t \\
0, \text { the economy is in expansion at time } t
\end{array}\right.
$$

for $t=1,2, \ldots . ., n$, the range of the monthly observations.

Denoting the conditional expectation $E_{t-1}\left(s_{t} \mid \Omega_{t-1}\right)$ in the information set $\Omega_{t-1}$ at time $t-1$, the conditional probability that the market is in a recession is:

$$
p_{t}=E_{t-1}\left(s_{t} \mid \Omega_{t-1}\right)=P_{t-1}\left(s_{t}=1\right)=\Phi\left(\pi_{t}\right)
$$


where $\pi_{t}$ is a linear combination of variables and $\Phi(\cdot)$ is the normal cumulative distribution function. Naturally, the conditional probability of a recession is the complement of the probability that the economy is not in recession, $P_{t-1}\left(s_{t}=0\right)=$ $1-p_{t}$. In order to predict the linear function, $\pi_{t}$, we study both static and dynamic models, with the simplest form defined as the We use as the benchmark the univariate probit model (Chen, 2009):

$$
\pi_{t}=\omega+\boldsymbol{x}_{t-h}^{\prime} \boldsymbol{\beta}
$$

where $\omega$ is a constant, $\beta$ is the coefficients vector, and $\chi_{t-h}$ is a matrix of predictive regressors. The index $h$ denotes the forecasting horizon. The popular static model can be extended by adding lags of the state variable, $s_{t}$, resulting to the dynamic autoregressive model

$$
\pi_{t}=\omega+\alpha\left(s_{t-1}\right)+\boldsymbol{x}_{t-\boldsymbol{h}}^{\prime} \boldsymbol{\beta}
$$

or by adding lags of the dependent variable, $\pi_{t}$, to the dynamic autoregressive model (Kauppi and Saikkonen, 2008):

$$
\pi_{t}=\omega+\delta\left(\pi_{t-1}\right)+\boldsymbol{x}_{t-\boldsymbol{h}}^{\prime} \boldsymbol{\beta}
$$

By recursive substitution, equation (14) can be seen as an infinite order static equation (13), where the entire history of the values of the predictive variables has an effect $\chi_{t-h}$ on the conditional probability. Thus, if the longer history of explanatory variables included in $\chi_{t-h}$ is useful to predict the future market status, the autoregressive equation (15) may offer a parsimonious way of specifying the predictive model. A natural extension would be the dynamic autoregressive model:

$$
\pi_{t}=\omega+\alpha\left(s_{t-1}\right)+\delta\left(\pi_{t-1}\right)+\boldsymbol{x}_{t-\boldsymbol{h}}^{\prime} \boldsymbol{\beta}
$$

Of course, one could consider higher order lags of variables $s_{t}$ and $\pi_{t}$ but as argued in Kauppi and Saikkonen (2008) a first-order lag structure usually suffices. Detailed description on the estimation of the models are reported on the Appendix.

\section{Empirical Results}

We built our forecasting models starting with a simple model consisting of only a constant term and add the real (or nominal) oil prices and stock returns, the term spread, the future expected term spread, and the term premium. Thus, following the 
notation of our probit models, the regressors' matrix and the coefficients' vector would be $\boldsymbol{x}_{\boldsymbol{t}-\boldsymbol{h}}=\left\{\omega, \Delta(\ln (W T I)), \Delta(\ln (S P 500)), T S, E_{t-h}(T S), T P\right\}$ and $\boldsymbol{\beta}=$ $\left\{1, \gamma_{1}, \gamma_{2}, \gamma_{3}, \gamma_{4}, \gamma_{5}\right\}$ included recursively. For the oil and stock price returns, we consider either real or nominal prices.

In order to measure the statistical significance of each model, we perform a recursive Likelihood Ratio (LR) test, comparing the log-likelihood between the constrained, 'poorer' model with fewer regressors against a 'richer', unconstrained model with more explanatory variables. The null hypothesis is that the restricted model predicts more accurately than the unrestricted one. We forecast recessions for $h=1,3,6,12,24$ and 36 months ahead. All models are trained in the period January 1871-December 1945 (901 observations), while the period January 1946 - June 2016 (845 observations) is kept aside for out-of-sample forecasting. An alternative approach would be to evaluate the forecasting accuracy of all models using a rolling window approach, but that would require a significant amount of computational capacity cost and time for the implementation of the machine learning methodology. ${ }^{6}$

A characteristic that makes recession forecasting difficult is the significant lag between the economy entering a recession and the official announcement from the NBER. In fact, the lag between a recession occurring and the recognition of such an incident can be up to 12 months. In order to overcome this, we use a combination of iterative and direct forecasts to obtain unbiased out-of-sample results. More specifically, we train our models on the pre-WWII dataset and then, keeping all coefficients fixed, we obtain one-period-ahead probability forecasts, treating each forecast as the 'observed' value for the next forecast (dynamic forecasting). These forecasts are used as the 'quasi-lagged' probability or state (NBER recessions) values in order to obtain the direct forecast of the forecasting horizon. For instance, let us assume that we forecast the state of the economy on January 1976 using the NBER index in January 1975 (12 months ahead). In the case of probit models, we train models that include the 'quasi-lagged' probabilities (or state variable 0 or 1 ) on December 1975 and the actual data observed in January 1975. When we consider SVM models, we eonstrain-use onlyte "forecasted" lagged state variables, since the

\footnotetext{
${ }^{6}$ The computational cost is based on the need to train approximately $4.9 \times 10^{9}$ models for each of the 1625 windows in order to fine-tune each SVM model.
} 
SVM methodology is not a probabilistic methodology per se (we obtain the probability estimates of the forecasts on a second step).

We evaluate the forecasting accuracy of each model according to the quadratic probability score (QPS) (Diebold and Rudebusch, 1989):

$$
Q P S=\frac{1}{m} \sum_{t=1}^{m} 2\left(s_{t}-E_{t-h}\left(s_{t}\right)\right)^{2}
$$

where $E_{t-h}\left(s_{t}\right)=E_{t-h}\left(\Phi\left(\pi_{t}\right)\right)$ and $m$ is the sample length. The QPS can be seen as the equivalent to the Mean Square Error for classification models. It ranges from 0 to 2, with smaller prices denoting smaller forecasting errors. In Table 1, we report the insample QPS statistic for the static and dynamic probit models that are statistically significant at the $5 \%$ level of significance. For comparison reasons we also report the QPS of a naive forecaster who assumes that the economy is always in expansion. These models fail to detect recessions altogether. ${ }^{7}$

As we can observe from Table 1, models of oil and stock returns cannot outperform a constant only-model with only a constant. In contrast, adding the term spread (TS) leads to statistically significant models of higher accuracy more accurate models with statistical significance.. The same applies $\underline{A}$ for up to 6 months ahead forecasting using the term premium (TP), but not with the inclusion of the expected term spread $\left(E_{t-h}(T S)\right)$. Regarding the model structure, we observe that the dynamic AR model expressions of equations (15) and (18) outperformed the static (14) and the dynamic AR (16) models (with the inclusion of only the lagged probability). Nevertheless, the true forecasting ability of a model is measured in out-of-sample forecasting (Table 2).

The reported QPS statistic is higher for longer forecasting horizons, as expected due to the higher uncertainty of long-term forecasts over shorter ones. Again, we observe that the most accurate forecasting models are the ones that include the first lag of the state variable $s_{t-1}$ as a regressor. We find no significant difference in the forecasting error using nominal or real prices for oil and stock returns. In contrast, a significant increase in the forecasting ability comes with the inclusion of the term spread.

\footnotetext{
${ }^{7}$ Following the suggestions of an anonymous referee, we repeated all forecast evaluations using the Giacomini and White (2006) conditional predictive test. The results are quantitatively similar to the QPS statistic. Complete details of these results are reported in the Appendix.
} 
In Tables 3 and 4, we depict the QPS statistics of an SVM-linear model in insample and out-of-sample forecasting, respectively. Motivated by the high accuracy of the first lag of the state variable, $s_{t-1}$, we train models that include only independent variables as regressors (coded 'Static') and models that also include past values of the state variable (coded 'AR'). We use the iterative approach to forecast the values of the first lag of the state variable when forecasting further-longer than one month ahead. The reported results are all statistically significant at the $5 \%$ level of significance according to our LR tests. The results of the SVR-linear model indicate the same pattern produced by the probit models: the inclusion of the lagged state variable exhibits the smallest forecasting error. The in-sample and out-of-sample QPS statistics for the SVM-RBF model are reported in Tables 5 and 6, respectively.

The forecasting results based on the RBF kernel do not improve the forecasting accuracy over the probit or the SVR-linear models. Again, the most accurate models are the ones that include the first lag of the state variable. Nominal prices for oil and stock returns exhibit marginally higher out-of-sample forecasting accuracy than that obtained using real prices. Given the volume of the reported results, in Table 7 , we present the models that exhibit the highest out-of-sample forecasting accuracy per forecasting horizon for the probit and SVR methodologies. In cases where two or more models exhibit similar forecasting accuracy, we follow an Occam's razor approach, selecting the models with the highest parsimony (fewer input variables).

As we observe from Table 7, the probit models foresee recession periods more accurately than SVM models for up to six months ahead, while the SVM models are more accurate over longer horizons. The most accurate forecasting model is the one that includes oil and stock returns, as well as the term spread, while the expected term spread and the term premium add to the forecasting ability of the best models only in short-term forecasting. Given the significant delay between the economy entering into recession and the reflection of this fact oin the economic indicators-of the monetary authority, short-term forecasting is of interest to policy makers only in forming an

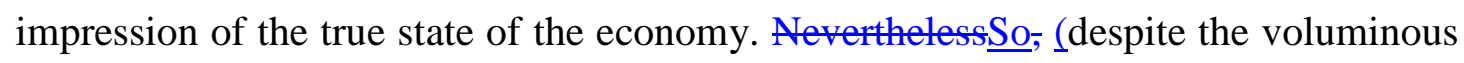
literature on short-term and now-cast forecasting;) we treat short-term forecasts as signs and not as definite results, following the NBER methodology of delaying 
definite results and focusing on long-term resultsforecasts. Thus, the stability of the AR SVM-RBF models in long-term forecasting seems ideal for using it such a methodology as an early warning mechanism of future-upcoming recessions.

Another interesting result is the difference in the QPS values between the preand post-WWII datasets. There is a vast literature suggesting a significant change in the behaviour of business cycles between these two periods. Although our results suggest that post-WWII recessions are easier to forecast, they are in-sample and outof-sample forecasts and therefore these comparisons should be treated with caution. This is however a viable path for future research. In Figures 4 and 5, we depict the forecasted probabilities of recession for the dynamic probit and SVM-RBF models of Table 7.

Both dynamic probit and SVM models forecast recession periods accurately, since they appear to have a probability of recession higher than $50 \%$ in each period. An exception is the three-month-ahead SVM model that produces many false positive results. Interestingly, the SVM models appear to discriminate between recessions and tranquil periods better than probit models do, since the forecasted probabilities between the two periods have a sharp difference.

\section{Conclusion}

The objective of this paper is to determine to what extent a selection of leading indicators is able to forecast U.S. recessions. In doing so we examine linear dynamic probit and nonlinear Support Vector Machines (SVM) classification models, using monthly data from January 1871 to June 2016. We consider a variety of leading indicators, such as the yield spread, oil price shocks, stock returns and the term

premium analysing the forecasting ability foref each of them. To define recessions, we follow the business cycle chronology proposed by the National Bureau of Economic Research (NBER). In order to evaluate the accuracy of our predictions, the study both in-sample and out-of-sample Quadratic Probability Scores.

Our findings suggest that the probit models predict U.S. recession periods more accurately than the SVM models for up to six months ahead, while the SVM models are more accurate over longer horizons. Furthermore, the most accurate forecasting models use the term spread, and oil and stock returns as regressors. 
Taking into accountAs we argue, the existence of a significant delay between the economy entering into recession and its reflection ton the-economic indicators-of the monetary authority, short-term forecasting could be of limited use. Furthermore, SVM models appear to discriminate between recessions and tranquil periods better than probit models do. Therefore, according to our results, SVM models seem more appropriate for predicting economic recessions than the usually employed probit models.

Our empirical application could be further extended with a rolling window approach, which may provide us with information on changes in the behaviour of the business cycles over time, but this is a matter for future research, given the amount of computational time required for estimating these nonlinear models over such a long historical sample. Another interesting-viable path for future work could involve the application of other machine learning methodologies, which may give us a classification boundary between expansions and recessions, thus providing rules of thumb for interpreting fluctuations in oil and stock prices and other macroeconomic variables. 


\section{References}

Ang, A., Piazzesi, M., and Wei, M., 2006. What does the yield curve tell us about GDP? Journal of Economics 131, 1-2.

Berge, T.J., 2015. Predicting Recessions with Leading Indicators: Model Averaging and Selection over the Business Cycle, Journal of Forecasting 34, 455-471.

Berge, T. J., \& Jordà, Ò., 2011. Evaluating the classification of economic activity into recessions and expansions. American Economic Journal: Macroeconomics 3, 246277.

Bernanke, B.S., and Blinder, A.S., 1992. The Federal funds rate and the channels of monetary transmission. American Economic Review 82, 901-927.

Chang, C.-C., and Lin, C-J, 2011. LIBSVM: a library for support vector machines. ACM Transactions on Intelligent Systems and Technology, 2, 1-27.

Chen, S.S., 2009. Predicting the bear market: macroeconomic variables as leading indicators. Journal of Banking and Finance 33, 211-223.

Chauvet, M., and Potter, S., 2005. Forecasting recessions using the yield curve. Journal of Forecasting 24, 77-103.

Clark, T., and West, K., 2007. Approximately Normal Tests for Equal Predictive Accuracy in Nested Models, Journal of Econometrics 138, 291-311.

Cortes, C., and Vapnik, V., 1995. Support-Vector Networks, Machine Learning 20, 273-297.

Diebold, F.X., Rudebusch, G.D., 1989. Scoring the leading indicators. Journal of Business 62, 369-391.

Dueker, M.J., 1997. Strengthening the case for the yield curve as a predictor of U.S. recessions. St. Louis Federal Review, 41-51.

Dueker, M.J., 2005. Dynamic forecasts of qualitative variables: A Qual VAR model of U.S. recessions. Journal of Business and Economic Statistics 23, 96-104.

Engemann, K. M., Kliesen, K. L., and Owyang, M. T., 2010. Do Oil Shocks Drive Business Cycles? Some U.S. and International Evidence. Federal Reserve Bank of St. Louis Working Paper Series 2010 007A. 
Estrella, A. and Hardouvelis, G. A., 1991. The term structure as a predictor of real economic activity. Journal of Finance 46, 555-576.

Estrella, A. and Mishkin, F. S., 1998. Predicting US recessions: Financial variables as leading indicators. The Review of Economics and Statistics 80, 45-61.

Gadea, M.D. and Perez-Quiros, G., 2015. The failure to predict the Great Recession. A view through the role of credit. Journal of the European Economic Association 13, 534-559.

Gertler, M. and Lown, C. S., 1999. The information in the high-yield bond spread for the business cycle: evidence and some implications. Oxford Review of Economic Policy 15, 132-150.

Giacomini, R. and Rossi, B., 2006. How stable is the forecasting performance of the yield curve for output growth? Oxford Bulletin of Economics and Statistic 68, 783795.

Giacomini, R. and White, H., 2006. Test of Conditional Predictive Ability, Econometrica 74, 1545-1578.

Gogas, P., Papadimitriou, T., and Chrysanthidou, E., 2015. Yield Curve Point Triplets in Recession Forecasting, International Finance 18, 207-226.

Hamilton, J.D., 2011. Calling recessions in real time. International Journal of Forecasting 27, 1006-1026.

Hamilton, J. D. and Kim, D. H., 2002. A re-examination of the predictability of the yield spread for real economic activity. Journal of Money, Credit, and Banking 34, 340-360.

Harvey, C. R., 1988. The real term structure and consumption growth. Journal of Financial Economics 22, 305-333.

Harvey, C. R., 1989. Forecasts of Economic Growth from the Bond and Stock Markets. Financial Analysts Journal 45, 38-45.

International Monetary Fund, 2009. World Economic Outlook, April 2009.

Kauppi, H. and Saikkonen, P., 2008. Predicting U.S. recessions with dynamic binary response models. The Review of Economics and Statistics 90, 777-791. 
Killian, L. and Vigfusson R., 2013. Do oil prices help forecast U.S. real GDP? The role of nonlinearities and asymmetries. Journal of Business and Economic Statistics 31, 78-93.

Levanon, G., Manini, J.C., Ozyildirim, A., Schaitkin, B., and Tanchua, J., 2015. Using a leading credit index to predict turning points in the US business cycle. International Journal of Forecasting 31, 392-398.

Liu, W. and Moench, E., 2016. What predicts US recessions? International Journal of Forecasting 32, 1138-1150.

McCracken, W., 2007. Asymptotics for out of sample tests of Granger causality, Journal of Econometrics 140, 719-752.

Mody, A. and Taylor, M. P., 2003. The high-yield spread as a predictor of real economic activity: evidence of a financial accelerator for the United States. IMF Staff Papers 50, 373-402.

Platt J., 2000. Probabilistic Output for Support Vector Machines and comparison to Regularized Log Likelihood Methods. In: A. Smola, P. Bartlett, B. Schölkopf, and D. Schuurmans (eds.): Advances in Large Margin Classifiers. Cambridge, MA.

Rossi, B. and Sekhposyan, T., 2011. Have economic models' forecasting performance for US output growth and inflation changed over time, and when? International Journal of Forecasting 26, 808-835.

Rudebusch, G.D. and Williams, J.C., 2009. Forecasting recessions: the puzzle of the enduring power of the yield curve. Journal of Business and Economic Statistics 27, 492-503.

Stock, J. H. and Watson, M. W., 1989. New indexes of coincident and leading economic indicators. In NBER Macroeconomics Annual, 4, 351-409. National Bureau of Economic Research, Inc., NBER Chapters.

Stock, J. H. and Watson, M. W., 2003. Forecasting output and inflation: the role of asset prices. Journal of Economic Literature 41, 788-829. 


\begin{tabular}{|c|c|c|c|c|c|c|c|c|}
\hline & & & $2=0$ & & & & & \\
\hline & & (11 1 & 115 & 11 (1) & 1112 & II & $11<-7$ & $11-50$ \\
\hline$\{\omega\}$ & & 0.493 & 0.493 & 0.494 & 0.494 & 0.495 & 0.495 & 0.496 \\
\hline \multicolumn{9}{|c|}{ Real Prices } \\
\hline \multirow{4}{*}{$\omega, \Delta(\ln (W T I)), \Delta(\ln (S P 500))$} & Static & & & & & 0.494 & & 0.495 \\
\hline & AR Static & & 0.212 & & & & & \\
\hline & Dynamic & & & & & & & 0.495 \\
\hline & AR Dynamic & 0.077 & 0.212 & & & & & \\
\hline \multirow{4}{*}{$\begin{array}{c}\omega, \Delta(\ln (W T I)), \Delta(\ln (S P 500)), \\
T S\end{array}$} & Static & 0.471 & 0.471 & 0.477 & 0.488 & 0.493 & 0.484 & 0.495 \\
\hline & AR Static & 0.077 & 0.212 & 0.356 & 0.472 & 0.478 & 0.466 & 0.479 \\
\hline & Dynamic & 0.397 & 0.414 & 0.441 & 0.483 & 0.442 & 0.444 & 0.495 \\
\hline & AR Dynamic & 0.077 & 0.212 & 0.355 & 0.405 & & & 0.430 \\
\hline \multirow{4}{*}{$\begin{array}{c}\omega, \Delta(\ln (W T I)), \Delta(\ln (S P 500)), \\
T S, E_{t-h}(T S)\end{array}$} & Static & & & & & & & \\
\hline & AR Static & & & & & & & \\
\hline & Dynamic & & & & & & & \\
\hline & AR Dynamic & 0.076 & & & & & & \\
\hline \multirow{4}{*}{$\begin{array}{c}\omega, \Delta(\ln (W T I)), \Delta(\ln (S P 500)), \\
T S, E_{t-h}(T S), T P\end{array}$} & Static & & 0.429 & 0.430 & & & & \\
\hline & AR Static & 0.076 & 0.204 & 0.338 & & 0.441 & 0.425 & \\
\hline & Dynamic & 0.353 & 0.368 & 0.396 & & 0.416 & & 0.425 \\
\hline & AR Dynamic & 0.076 & 0.204 & 0.341 & & & & 0.351 \\
\hline \multicolumn{9}{|c|}{ Nominal Prices } \\
\hline \multirow{4}{*}{$\omega, \Delta(\ln (W T I)), \Delta(\ln (S P 500))$} & Static & & & & & 0.494 & & 0.494 \\
\hline & AR Static & & 0.212 & & & & & \\
\hline & Dynamic & & & & & & & \\
\hline & AR Dynamic & 0.077 & 0.213 & 0.356 & & & & \\
\hline \multirow{4}{*}{$\begin{array}{c}\omega, \Delta(\ln (W T I)), \Delta(\ln (S P 500))) \\
T S\end{array}$} & Static & 0.460 & 0.462 & 0.472 & 0.487 & 0.493 & 0.486 & 0.494 \\
\hline & AR Static & 0.077 & 0.212 & 0.354 & 0.461 & & & \\
\hline & Dynamic & 0.362 & 0.393 & 0.435 & 0.480 & 0.416 & & \\
\hline & AR Dynamic & 0.077 & 0.212 & 0.354 & 0.393 & & & 0.403 \\
\hline \multirow{4}{*}{$\begin{array}{c}\omega, \Delta(\ln (W T I)), \Delta(\ln (S P 500))) \\
T S, E_{t-h}(T S)\end{array}$} & Static & & & & & & & \\
\hline & AR Static & & & & & & & \\
\hline & Dynamic & & & & & & & \\
\hline & AR Dynamic & 0.076 & & & & & & \\
\hline \multirow{4}{*}{$\begin{array}{c}\omega, \Delta(\ln (W T I)), \Delta(\ln (S P 500)), \\
T S, E_{t-h}(T S), T P\end{array}$} & Static & 0.428 & 0.421 & 0.424 & & & & \\
\hline & AR Static & 0.076 & 0.204 & 0.335 & 0.423 & & & \\
\hline & Dynamic & 0.326 & 0.352 & 0.390 & & & & 0.421 \\
\hline & AR Dynamic & 0.076 & 0.204 & 0.333 & & & & 0.340 \\
\hline Naïve model & \multicolumn{8}{|c|}{0.880} \\
\hline
\end{tabular}

Note: The 'Static' model corresponds with the model of equation (18), 'AR Static' with the model of equation (19), 'Dynamic' with model (20) and 'AR Dynamic' with equation (21). We reported only the statistically significant results at the 5\% level of significance according to the LR test of model specification. We compared the log-likelihood between the constrained 'poorer' model with fewer regressors against a 'richer' unconstrained model where we considered more explanatory variables following augmentation of the variable matrix in the order indicated in the table. The null hypothesis is that the restricted model predicts better than the unrestricted one. We did not use tests based on the Mean Square Error (MSE), as do Clark and West (2007), and McCracken (2007), since SVM models produce only directional forecasts, where an MSE is not applicable. 


\begin{tabular}{|c|c|c|c|c|c|c|c|c|}
\hline Variables $\left(\chi_{t-h}\right)$ & Model & $\mathrm{h}=1$ & $\mathrm{~h}=3$ & $\mathrm{~h}=6$ & $\mathrm{~h}=12$ & $\mathrm{~h}=18$ & $\mathrm{~h}=24$ & $\mathrm{~h}=36$ \\
\hline$\{\omega\}$ & & 0.426 & 0.427 & 0.429 & 0.432 & 0.436 & 0.440 & 0.440 \\
\hline \multicolumn{9}{|c|}{$\underline{\text { Real Prices }}$} \\
\hline \multirow{4}{*}{$\omega, \Delta(\ln (W T I)), \Delta(\ln (S P 500))$} & Static & & & & & 0.435 & & 0.439 \\
\hline & AR Static & & 0.065 & & & & & \\
\hline & Dynamic & & & & & & & 0.426 \\
\hline & AR Dynamic & 0.050 & 0.064 & & & & & \\
\hline \multirow{4}{*}{$\begin{array}{c}\omega, \Delta(\ln (W T I)), \Delta(\ln (S P 500)), \\
T S\end{array}$} & Static & 0.419 & 0.410 & 0.410 & 0.426 & 0.434 & 0.443 & 0.439 \\
\hline & AR Static & 0.050 & 0.064 & 0.129 & 0.309 & 0.321 & 0.320 & 0.324 \\
\hline & Dynamic & 0.438 & 0.431 & 0.439 & 0.448 & 0.505 & 0.503 & 0.428 \\
\hline & AR Dynamic & 0.050 & 0.063 & 0.127 & 0.200 & & & 0.215 \\
\hline \multirow{4}{*}{$\begin{array}{c}\omega, \Delta(\ln (W T I)), \Delta(\ln (S P 500)), \\
T S, E_{t-h}(T S)\end{array}$} & Static & & & & & & & \\
\hline & AR Static & & & & & & & \\
\hline & Dynamic & & & & & & & \\
\hline & AR Dynamic & 0.048 & & & & & & \\
\hline \multirow{4}{*}{$\begin{array}{c}\omega, \Delta(\ln (W T I)), \Delta(\ln (S P 500)), \\
T S, E_{t-h}(T S), T P\end{array}$} & Static & & 0.541 & 0.497 & & & & \\
\hline & AR Static & 0.048 & 0.057 & 0.128 & & 0.476 & 0.463 & \\
\hline & Dynamic & 0.409 & 0.401 & 0.424 & & 0.510 & & 0.511 \\
\hline & AR Dynamic & 0.048 & 0.057 & 0.127 & & & & 0.290 \\
\hline \multicolumn{9}{|c|}{ Nominal Prices } \\
\hline \multirow{4}{*}{$\omega, \Delta(\ln (W T I)), \Delta(\ln (S P 500))$} & Static & & & & & 0.437 & & 0.440 \\
\hline & AR Static & & 0.065 & & & & & \\
\hline & Dynamic & & & & & & & \\
\hline & AR Dynamic & 0.050 & 0.064 & 0.125 & & & & \\
\hline \multirow{4}{*}{$\omega, \Delta(\ln (W T I)), \Delta(\ln (S P 500))}$, & Static & 0.402 & 0.395 & 0.401 & 0.422 & 0.437 & 0.448 & 0.440 \\
\hline & AR Static & 0.050 & 0.064 & 0.127 & 0.276 & & & \\
\hline & Dynamic & 0.416 & 0.409 & 0.424 & 0.448 & 0.513 & & \\
\hline & AR Dynamic & 0.050 & 0.063 & 0.125 & 0.185 & & & 0.199 \\
\hline \multirow{4}{*}{$\begin{array}{c}\omega, \Delta(\ln (W T I)), \Delta(\ln (S P 500)), \\
T S, E_{t-h}(T S)\end{array}$} & Static & & & & & & & \\
\hline & AR Static & & & & & & & \\
\hline & Dynamic & & & & & & & \\
\hline & AR Dynamic & 0.048 & & & & & & \\
\hline \multirow{4}{*}{$\begin{array}{c}\omega, \Delta(\ln (W T I)), \Delta(\ln (S P 500)), \\
T S, E_{t-h}(T S), T P\end{array}$} & Static & 0.493 & 0.434 & 0.434 & & & & \\
\hline & AR Static & 0.048 & 0.059 & 0.131 & 0.301 & & & \\
\hline & Dynamic & 0.367 & 0.358 & 0.390 & & & & 0.502 \\
\hline & AR Dynamic & 0.048 & 0.059 & 0.124 & & & & 0.263 \\
\hline Naïve model & \multicolumn{8}{|c|}{0.315} \\
\hline
\end{tabular}

Note: Static model corresponds with the model of equation (14), AR Static with the model of equation (15), Dynamic with model (16) and AR Dynamic with model (17). We reported only the statistically significant results at the 5\% level of significance, according to the LR test of model specification. We compared the log-likelihood between the constrained 'poorer' model with fewer regressors against a 'richer' unconstrained model where we considered more explanatory variables following the augmentation of the variable matrix in the order discussed in the table. The null hypothesis is that the restricted model predicts better than the unrestricted one. We did not use tests based on the Mean Square Error (MSE), as do Clark and West (2007) and McCracken (2007), since SVM models produce only directional forecasts where a MSE is not applicable. The 'naïve model' refers to a naïve forecaster who assumes that the economy is always in expansion. 


\begin{tabular}{|c|c|c|c|c|c|c|c|c|}
\hline Variables $\left(\chi_{t-h}\right)$ & Model & $\mathrm{h}=1$ & $\mathrm{~h}=3$ & $\mathrm{~h}=6$ & $\mathrm{~h}=12$ & $\mathrm{~h}=18$ & $\mathrm{~h}=24$ & $\mathrm{~h}=36$ \\
\hline$\{\omega\}$ & & 0.493 & 0.493 & 0.494 & 0.494 & 0.495 & 0.495 & 0.496 \\
\hline \multicolumn{9}{|c|}{ Real Prices } \\
\hline \multirow{2}{*}{$\omega, \Delta(\ln (W T I)), \Delta(\ln (S P 500))$} & Static & 0.478 & 0.472 & 0.482 & 0.494 & 0.495 & 0.496 & 0.497 \\
\hline & AR & 0.077 & 0.147 & 0.148 & 0.149 & 0.150 & 0.151 & 0.149 \\
\hline \multirow{2}{*}{$\begin{array}{c}\omega, \Delta(\ln (W T I)), \Delta(\ln (S P 500)), \\
T S\end{array}$} & Static & 0.473 & 0.472 & 0.482 & 0.494 & 0.495 & 0.496 & 0.496 \\
\hline & AR & 0.077 & 0.147 & 0.148 & 0.149 & 0.150 & 0.151 & 0.149 \\
\hline \multirow{2}{*}{$\begin{array}{c}\omega, \Delta(\ln (W T I)), \Delta(\ln (S P 500)), \\
T S, E_{t-h}(T S)\end{array}$} & Static & 0.445 & 0.434 & 0.434 & 0.464 & 0.495 & 0.494 & 0.448 \\
\hline & AR & 0.077 & 0.147 & 0.148 & 0.149 & 0.150 & 0.151 & 0.149 \\
\hline \multirow{2}{*}{$\begin{array}{c}\omega, \Delta(\ln (W T I)), \Delta(\ln (S P 500)), \\
T S, E_{t-h}(T S), T P\end{array}$} & Static & 0.439 & 0.429 & 0.429 & 0.458 & 0.481 & 0.461 & 0.437 \\
\hline & $\mathrm{AR}$ & 0.077 & 0.147 & 0.148 & 0.149 & 0.150 & 0.151 & 0.149 \\
\hline \multicolumn{9}{|c|}{ Nominal Prices } \\
\hline \multirow{2}{*}{$\omega, \Delta(\ln (W T I)), \Delta(\ln (S P 500))$} & Static & 0.464 & 0.464 & 0.473 & 0.494 & 0.495 & 0.496 & 0.499 \\
\hline & $\mathrm{AR}$ & 0.077 & 0.147 & 0.148 & 0.149 & 0.150 & 0.151 & 0.149 \\
\hline \multirow{2}{*}{$\begin{array}{c}(\omega, \Delta(\ln (W T I)), \Delta(\ln (S P 500)), \\
T S\end{array}$} & Static & 0.460 & 0.462 & 0.473 & 0.494 & 0.495 & 0.496 & 0.500 \\
\hline & AR & 0.077 & 0.147 & 0.148 & 0.149 & 0.150 & 0.151 & 0.149 \\
\hline \multirow{2}{*}{$\begin{array}{c}\omega, \Delta(\ln (W T I)), \Delta(\ln (S P 500)), \\
T S, E_{t-h}(T S), T P\end{array}$} & Static & 0.430 & 0.423 & 0.428 & 0.463 & 0.495 & 0.496 & 0.445 \\
\hline & AR & 0.077 & 0.147 & 0.148 & 0.149 & 0.150 & 0.151 & 0.149 \\
\hline \multirow{2}{*}{$\begin{array}{c}\omega, \Delta(\ln (W T I)), \Delta(\ln (S P 500)), \\
T S, E_{t-h}(T S), T P\end{array}$} & Static & 0.427 & 0.419 & 0.423 & 0.456 & 0.485 & 0.467 & 0.439 \\
\hline & AR & 0.077 & 0.147 & 0.148 & 0.149 & 0.150 & 0.151 & 0.149 \\
\hline Naïve model & \multicolumn{8}{|c|}{0.880} \\
\hline
\end{tabular}

Note: Static denotes models that include the various variables as regressors, while AR denotes the additional inclusion of the first lag of the state variable $s_{t-1}$. The reported are statistically significant at $5 \%$ level of significance according to an LR test of model specification. We compare the log-likelihood between the constrained "poorer" model with less regressors against a "richer" unconstrained model where we consider more explanatory variables following the augmentation of thee variable matrix in the order discussed in the Table. The null hypothesis is that the restricted model predicts better than the unrestricted one. We do not use tests based in the Mean Square Error (MSE) as Clark and West (2007) and McCracken (2007) since SVM models produce only directional forecasts where a MSE is not applicable. The naïve model refers to a naïve forecaster who assumes that the economy is always in expansion. 


\begin{tabular}{|c|c|c|c|c|c|c|c|c|}
\hline Variables $\left(\chi_{t-h}\right)$ & Model & $\mathrm{h}=1$ & $\mathrm{~h}=3$ & $\mathrm{~h}=6$ & $\mathrm{~h}=12$ & $\mathrm{~h}=18$ & $\mathrm{~h}=24$ & $\mathrm{~h}=36$ \\
\hline$\{\omega\}$ & & 0.426 & 0.427 & 0.428 & 0.432 & 0.436 & 0.439 & 0.441 \\
\hline \multicolumn{9}{|c|}{ Real Prices } \\
\hline \multirow{2}{*}{$\omega, \Delta(\ln (W T I)), \Delta(\ln (S P 500))$} & Static & 0.429 & 0.421 & 0.422 & 0.438 & 0.433 & 0.448 & 0.415 \\
\hline & AR & 0.051 & 0.099 & 0.099 & 0.099 & 0.099 & 0.099 & 0.099 \\
\hline \multirow{2}{*}{ 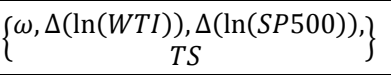 } & Static & 0.425 & 0.427 & 0.421 & 0.436 & 0.435 & 0.448 & 0.440 \\
\hline & AR & 0.051 & 0.099 & 0.099 & 0.099 & 0.099 & 0.099 & 0.099 \\
\hline \multirow{2}{*}{$\begin{array}{c}\omega, \Delta(\ln (W T I)), \Delta(\ln (S P 500)), \\
T S, E_{t-h}(T S)\end{array}$} & Static & 0.335 & 0.295 & 0.273 & 0.327 & 0.438 & 0.436 & 0.350 \\
\hline & AR & 0.051 & 0.099 & 0.099 & 0.099 & 0.099 & 0.099 & 0.099 \\
\hline \multirow{2}{*}{$\begin{array}{c}\omega, \Delta(\ln (W T I)), \Delta(\ln (S P 500)), \\
T S, E_{t-h}(T S), T P\end{array}$} & Static & 0.535 & 0.522 & 0.415 & 0.527 & 0.547 & 0.807 & 0.690 \\
\hline & AR & 0.051 & 0.099 & 0.099 & 0.099 & 0.099 & 0.099 & 0.099 \\
\hline \multicolumn{9}{|c|}{ Nominal Prices } \\
\hline \multirow{2}{*}{$\omega, \Delta(\ln (W T I)), \Delta(\ln (S P 500))$} & Static & 0.408 & 0.401 & 0.407 & 0.435 & 0.438 & 0.451 & 0.460 \\
\hline & AR & 0.051 & 0.099 & 0.099 & 0.099 & 0.099 & 0.099 & 0.099 \\
\hline \multirow{2}{*}{ 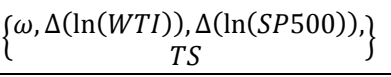 } & Static & 0.402 & 0.396 & 0.405 & 0.435 & 0.439 & 0.451 & 0.394 \\
\hline & AR & 0.051 & 0.099 & 0.099 & 0.099 & 0.099 & 0.099 & 0.099 \\
\hline \multirow{2}{*}{$\begin{array}{c}\omega, \Delta(\ln (W T I)), \Delta(\ln (S P 500)), \\
T S, E_{t-h}(T S), T P\end{array}$} & Static & 0.312 & 0.284 & 0.266 & 0.318 & 0.433 & 0.440 & 0.338 \\
\hline & $\mathrm{AR}$ & 0.051 & 0.099 & 0.099 & 0.099 & 0.099 & 0.099 & 0.099 \\
\hline \multirow{2}{*}{$\begin{array}{c}\omega, \Delta(\ln (W T I)), \Delta(\ln (S P 500))) \\
T S, E_{t-h}(T S), T P\end{array}$} & Static & 0.411 & 0.396 & 0.405 & 0.499 & 0.505 & 0.796 & 0.456 \\
\hline & $\mathrm{AR}$ & 0.051 & 0.099 & 0.099 & 0.099 & 0.099 & 0.099 & 0.099 \\
\hline
\end{tabular}

Note: Static denotes models that include the various variables as regressors, while AR denotes the additional inclusion of the first lag of the state variable $s_{t-1}$. The reported are statistically significant at $5 \%$ level of significance according to an LR test of model specification. We compare the log-likelihood between the constrained "poorer" model with less regressors against a "richer" unconstrained model where we consider more explanatory variables following the augmentation of thee variable matrix in the order discussed in the Table. The null hypothesis is that the restricted model predicts better than the unrestricted one. We do not use tests based in the Mean Square Error (MSE) as Clark and West (2007) and McCracken (2007) since SVM models produce only directional forecasts where a MSE is not applicable. The naïve model refers to a naïve forecaster who assumes that the economy is always in expansion. 


\begin{tabular}{|c|c|c|c|c|c|c|c|c|}
\hline Variables $\left(\chi_{t-h}\right)$ & Model & $\mathrm{h}=1$ & $\mathrm{~h}=3$ & $\mathrm{~h}=6$ & $\mathrm{~h}=12$ & $\mathrm{~h}=18$ & $\mathrm{~h}=24$ & $\mathrm{~h}=36$ \\
\hline$\{\omega\}$ & & 0.493 & 0.493 & 0.494 & 0.494 & 0.495 & 0.495 & 0.496 \\
\hline \multicolumn{9}{|c|}{ Real Prices } \\
\hline \multirow{2}{*}{$\omega, \Delta(\ln (W T I)), \Delta(\ln (S P 500))$} & Static & 0.472 & 0.472 & 0.461 & 0.483 & 0.491 & 0.454 & 0.469 \\
\hline & AR & 0.077 & 0.147 & 0.148 & 0.149 & 0.150 & 0.151 & 0.149 \\
\hline \multirow{2}{*}{$\begin{array}{c}\omega, \Delta(\ln (W T I)), \Delta(\ln (S P 500)), \\
T S\end{array}$} & Static & 0.461 & 0.458 & 0.409 & 0.457 & 0.491 & 0.447 & 0.458 \\
\hline & AR & 0.075 & 0.129 & 0.146 & 0.147 & 0.148 & 0.149 & 0.149 \\
\hline \multirow{2}{*}{$\begin{array}{c}\omega, \Delta(\ln (W T I)), \Delta(\ln (S P 500)), \\
T S, E_{t-h}(T S)\end{array}$} & Static & 0.404 & 0.409 & 0.415 & 0.441 & 0.291 & 0.271 & 0.407 \\
\hline & AR & 0.075 & & 0.146 & 0.147 & 0.148 & 0.149 & 0.149 \\
\hline \multirow{2}{*}{$\begin{array}{c}\omega, \Delta(\ln (W T I)), \Delta(\ln (S P 500)), \\
T S, E_{t-h}(T S), T P\end{array}$} & Static & 0.351 & 0.342 & 0.358 & 0.416 & 0.022 & 0.037 & \\
\hline & $\mathrm{AR}$ & 0.076 & 0.147 & 0.148 & 0.148 & 0.150 & 0.151 & 0.148 \\
\hline \multicolumn{9}{|c|}{ Nominal Prices } \\
\hline \multirow{2}{*}{$\omega, \Delta(\ln (W T I)), \Delta(\ln (S P 500))$} & Static & 0.453 & 0.455 & 0.463 & 0.488 & 0.487 & 0.473 & 0.491 \\
\hline & AR & 0.077 & 0.148 & 0.148 & 0.149 & 0.150 & 0.151 & 0.149 \\
\hline \multirow{2}{*}{$\begin{array}{c}(\omega, \Delta(\ln (W T I)), \Delta(\ln (S P 500)), \\
T S\end{array}$} & Static & 0.401 & 0.416 & 0.450 & 0.475 & 0.489 & 0.467 & 0.477 \\
\hline & AR & 0.075 & 0.146 & 0.146 & 0.147 & 0.148 & 0.149 & 0.149 \\
\hline \multirow{2}{*}{$\begin{array}{c}\omega, \Delta(\ln (W T I)), \Delta(\ln (S P 500)), \\
T S, E_{t-h}(T S), T P\end{array}$} & Static & & 0.332 & 0.326 & 0.407 & 0.399 & 0.428 & 0.446 \\
\hline & $\mathrm{AR}$ & 0.075 & 0.146 & 0.146 & 0.147 & 0.148 & 0.149 & 0.149 \\
\hline \multirow{2}{*}{$\begin{array}{c}\omega, \Delta(\ln (W T I)), \Delta(\ln (S P 500)), \\
T S, E_{t-h}(T S), T P\end{array}$} & Static & 0.397 & & & 0.414 & 0.291 & 0.220 & 0.424 \\
\hline & AR & 0.076 & 0.147 & 0.148 & 0.149 & 0.150 & 0.151 & 0.149 \\
\hline Naïve model & \multicolumn{8}{|c|}{0.880} \\
\hline
\end{tabular}

Note: Static denotes models that include the various variables as regressors, while AR denotes the additional inclusion of the first lag of the state variable $s_{t-1}$. The reported are statistically significant at $5 \%$ level of significance according to an LR test of model specification. We compare the log-likelihood between the constrained 'poorer' model with less regressors against a 'richer' unconstrained model where we consider more explanatory variables following the augmentation of thee variable matrix in the order discussed in the Table. The null hypothesis is that the restricted model predicts better than the unrestricted one. We do not use tests based in the Mean Square Error (MSE) as Clark and West (2007) and McCracken (2007) since SVM models produce only directional forecasts where a MSE is not applicable. The naïve model refers to a naïve forecaster who assumes that the economy is always in expansion. 


\begin{tabular}{|c|c|c|c|c|c|c|c|c|}
\hline Variables $\left(\chi_{t-h}\right)$ & Model & $\mathrm{h}=1$ & $h=3$ & $\mathrm{~h}=6$ & $\mathrm{~h}=12$ & $\mathrm{~h}=18$ & $\mathrm{~h}=24$ & $\mathrm{~h}=36$ \\
\hline$\{\omega\}$ & & 0.426 & 0.427 & 0.428 & 0.432 & 0.436 & 0.439 & 0.441 \\
\hline \multicolumn{9}{|c|}{$\underline{\text { Real Prices }}$} \\
\hline \multirow{2}{*}{$\omega, \Delta(\ln (W T I)), \Delta(\ln (S P 500))$} & Static & 0.431 & 0.490 & 0.422 & 0.430 & 0.438 & 0.473 & 0.558 \\
\hline & AR & 0.051 & 0.099 & 0.099 & 0.099 & 0.099 & 0.099 & 0.099 \\
\hline \multirow{2}{*}{$\begin{array}{c}(\omega, \Delta(\ln (W T I)), \Delta(\ln (S P 500)), \\
T S\end{array}$} & Static & 0.412 & 0.402 & 0.422 & 0.427 & 0.438 & 0.448 & 0.591 \\
\hline & AR & 0.051 & 0.133 & 0.099 & 0.099 & 0.099 & 0.124 & 0.100 \\
\hline \multirow{2}{*}{$\begin{array}{c}\omega, \Delta(\ln (W T I)), \Delta(\ln (S P 500)), \\
T S, E_{t-h}(T S)\end{array}$} & Static & 0.324 & 0.299 & 0.278 & 0.312 & 0.480 & 0.482 & 0.538 \\
\hline & AR & 0.051 & & 0.099 & 0.099 & 0.100 & 0.101 & 0.100 \\
\hline \multirow{2}{*}{$\begin{array}{c}\omega, \Delta(\ln (W T I)), \Delta(\ln (S P 500)), \\
T S, E_{t-h}(T S), T P\end{array}$} & Static & 0.682 & 0.763 & 0.657 & 0.478 & 0.434 & 0.450 & \\
\hline & AR & 0.097 & 0.148 & 0.152 & 0.137 & 0.146 & 0.157 & 0.258 \\
\hline \multicolumn{9}{|c|}{$\underline{\text { Nominal Prices }}$} \\
\hline \multirow{2}{*}{$\omega, \Delta(\ln (W T I)), \Delta(\ln (S P 500))$} & Static & 0.386 & 0.383 & 0.398 & 0.423 & 0.433 & 0.444 & 0.439 \\
\hline & AR & 0.051 & 0.098 & 0.099 & 0.099 & 0.099 & 0.099 & 0.099 \\
\hline \multirow{2}{*}{$\begin{array}{c}\{\omega, \Delta(\ln (W T I)), \Delta(\ln (S P 500)), \\
T S\end{array}$} & Static & 0.366 & 0.374 & 0.403 & 0.423 & 0.434 & 0.437 & 0.427 \\
\hline & AR & 0.051 & 0.098 & 0.098 & 0.099 & 0.099 & 0.099 & 0.099 \\
\hline \multirow{2}{*}{$\begin{array}{c}\omega, \Delta(\ln (W T I)), \Delta(\ln (S P 500)), \\
T S, E_{t-h}(T S), T P\end{array}$} & Static & & 0.336 & 0.318 & 0.338 & 0.444 & 0.403 & 0.339 \\
\hline & AR & 0.051 & 0.098 & 0.099 & 0.099 & 0.099 & 0.099 & 0.099 \\
\hline \multirow{2}{*}{$\begin{array}{c}\omega, \Delta(\ln (W T I)), \Delta(\ln (S P 500)), \\
T S, E_{t-h}(T S), T P\end{array}$} & Static & 0.376 & & & 0.342 & 0.424 & 0.453 & 0.659 \\
\hline & AR & 0.093 & 0.145 & 0.148 & 0.145 & 0.151 & 0.164 & 0.267 \\
\hline Naïve model & \multicolumn{8}{|c|}{0.315} \\
\hline
\end{tabular}

Note: Static denotes models that include the various variables as regressors, while AR denotes the additional inclusion of the first lag of the state variable $s_{t-1}$. The reported are statistically significant at $5 \%$ level of significance according to an LR test of model specification. We compare the log-likelihood between the constrained "poorer" model with less regressors against a "richer" unconstrained model where we consider more explanatory variables following the augmentation of thee variable matrix in the order discussed in the Table. The null hypothesis is that the restricted model predicts better than the unrestricted one. We do not use tests based in the Mean Square Error (MSE) as Clark and West (2007) and McCracken (2007) since SVM models produce only directional forecasts where a MSE is not applicable. The naïve model refers to a naïve forecaster who assumes that the economy is always in expansion. 


\begin{tabular}{|c|c|c|c|c|}
\hline Horizon & Variables $\left(\chi_{t-h}\right)$ & Model & $\begin{array}{l}\text { In-sample } \\
\text { QPS }\end{array}$ & $\begin{array}{c}\text { Out-of-sample } \\
\text { QPS }\end{array}$ \\
\hline \multicolumn{5}{|c|}{ Probit } \\
\hline 1 & $\left\{\begin{array}{c}\omega, \Delta(\ln (W T I)), \Delta(\ln (S P 500)), \\
T S, E_{t-h}(T S)\end{array}\right\}$ & AR Dynamic & 0.076 & 0.048 \\
\hline 3 & $\left\{\begin{array}{c}\omega, \Delta(\ln (W T I)), \Delta(\ln (S P 500)), \\
T S, E_{t-h}(T S), T P\end{array}\right\}$ & $\begin{array}{c}\text { AR Static } \\
\text { AR Dynamic }\end{array}$ & 0.204 & 0.057 \\
\hline 6 & $\left\{\begin{array}{c}\omega, \Delta(\ln (W T I)), \Delta(\ln (S P 500)), \\
T S, E_{t-h}(T S), T P\end{array}\right\}$ & AR Dynamic & 0.333 & 0.124 \\
\hline 12 & $\left\{\begin{array}{c}\omega, \Delta(\ln (W T I)), \Delta(\ln (S P 500)), \\
T S\end{array}\right\}$ & AR Dynamic & 0.393 & 0.124 \\
\hline 18 & $\left\{\begin{array}{c}\omega, \Delta(\ln (W T I)), \Delta(\ln (S P 500)), \\
T S\end{array}\right\}$ & AR Static & 0.478 & 0.321 \\
\hline 24 & $\{\omega, \Delta(\ln (W T I)), \Delta(\ln (S P 500))\}$, & AR Static & 0.466 & 0.320 \\
\hline 36 & $\left\{\begin{array}{c}\omega, \Delta(\ln (W T I)), \Delta(\ln (S P 500)), \\
T S\end{array}\right\}$ & AR Dynamic & 0.403 & 0.199 \\
\hline \multicolumn{5}{|c|}{ SVM } \\
\hline 1 & $\left\{\begin{array}{c}(\omega, \Delta(\ln (W T I)), \Delta(\ln (S P 500)), \\
T S\end{array}\right\}$ & AR RBF & 0.075 & 0.051 \\
\hline 3 & $\left\{\begin{array}{c}\omega, \Delta(\ln (W T I)), \Delta(\ln (S P 500)), \\
T S\end{array}\right\}$ & AR RBF & 0.146 & 0.098 \\
\hline 6 & $\{\omega, \Delta(\ln (W T I)), \Delta(\ln (S P 500))\}$, & AR RBF & 0.146 & 0.098 \\
\hline 12 & $\left\{\begin{array}{c}\omega, \Delta(\ln (W T I)), \Delta(\ln (S P 500)), \\
T S\end{array}\right\}$ & AR RBF & 0.147 & 0.099 \\
\hline 18 & $\{\omega, \Delta(\ln (W T I)), \Delta(\ln (S P 500))\}$, & AR RBF & 0.148 & 0.099 \\
\hline 24 & $\left\{\begin{array}{c}\omega, \Delta(\ln (W T I)), \Delta(\ln (S P 500)), \\
T S\end{array}\right\}$ & AR RBF & 0.141 & 0.099 \\
\hline 36 & $\{\omega, \Delta(\ln (W T I)), \Delta(\ln (S P 500))\}$, & $\begin{array}{c}\text { AR RBF } \\
\text { AR Linear }\end{array}$ & 0.149 & 0.099 \\
\hline & Naïve model & & 0.880 & 0.315 \\
\hline
\end{tabular}

Note: 'AR Static' refers to the model of equation (15), 'AR Dynamic' to model (17) and 'AR' denotes the additional inclusion of the first lag of the state variable $s_{t-1}$ in the SVM models. When models exhibit similar forecasting accuracy, we follow an Occam's razor approach, selecting the models with the highest parsimony (fewer variables) and the best in-sample and out-ofsample forecasting accuracy. The naïve model refers to a naïve forecaster who assumes that the economy is always in expansion. 


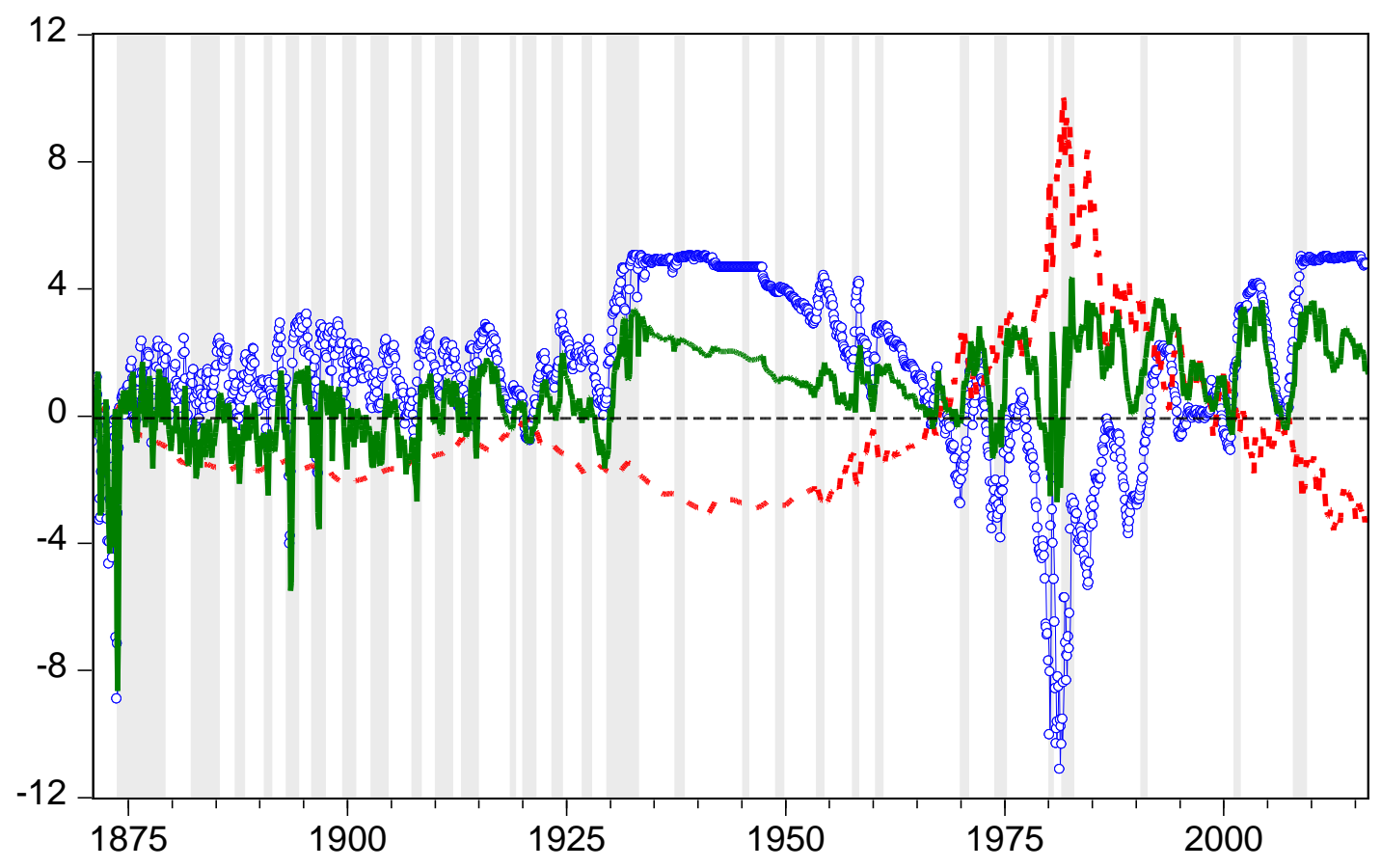

Figure 1: The term spread is depicted with the (green) continuous line, the dotted (blue) line with the circle markers depicts the expected short-term interest rate, and the (red) dashed line without markers depicts the term premium. The grey areas denote NBER recessions; colours are only present in the online version of the paper. 


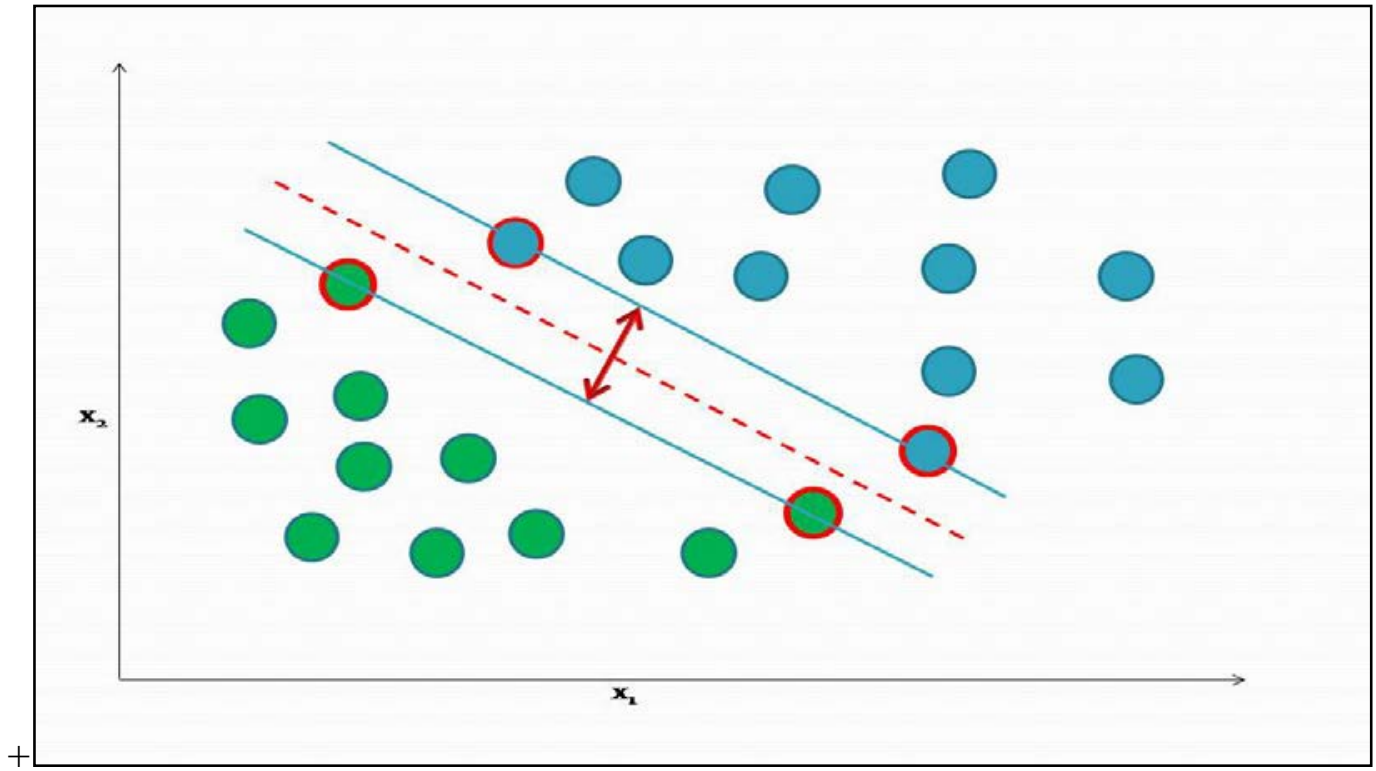

Figure 2: Hyperplane selection and support vectors. The SVs are indicated by the pronounced red circles, the margin lines are represented with the continuous lines, and the hyperplane is represented with the dotted line. 


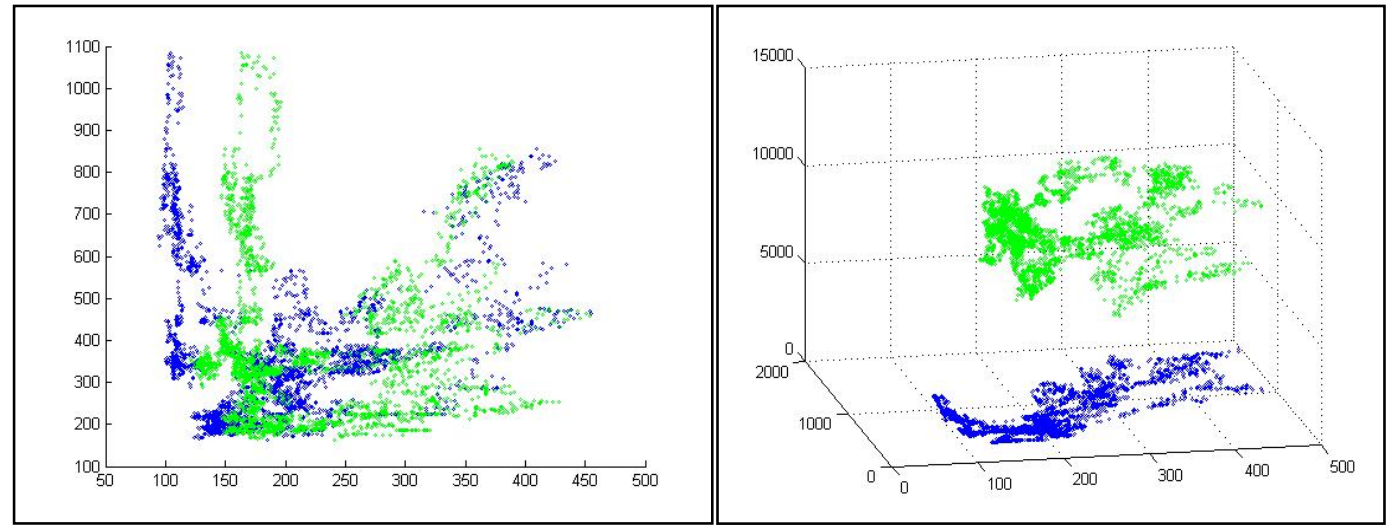

Figure 3: The data space: The non-separable two-class scenario (left) and the separable case in the feature space after the projection (right). 


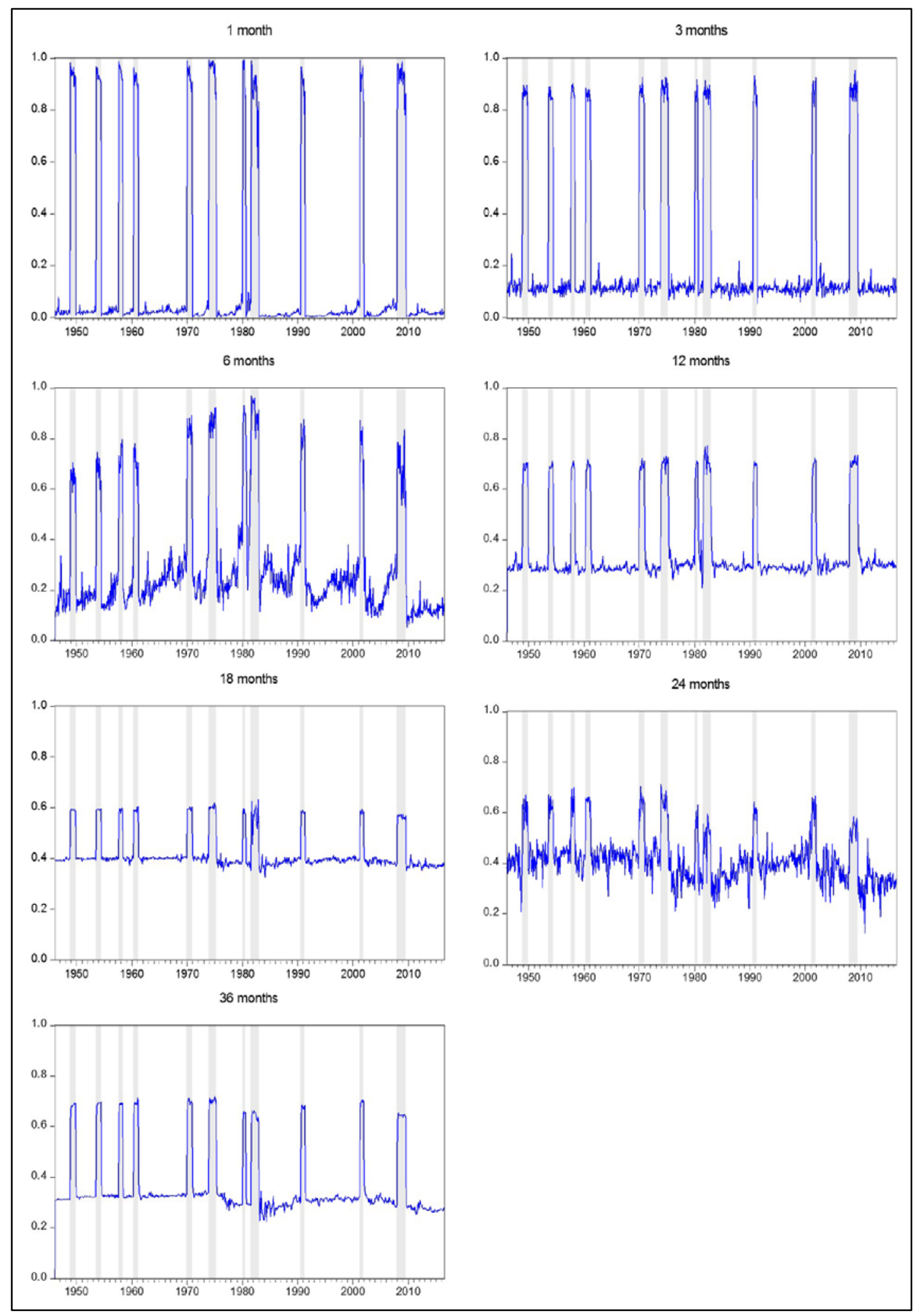

Figure 4: Out-of-sample forecasted probabilities of the dynamic probit models. Grey areas denote NBER recessions. 


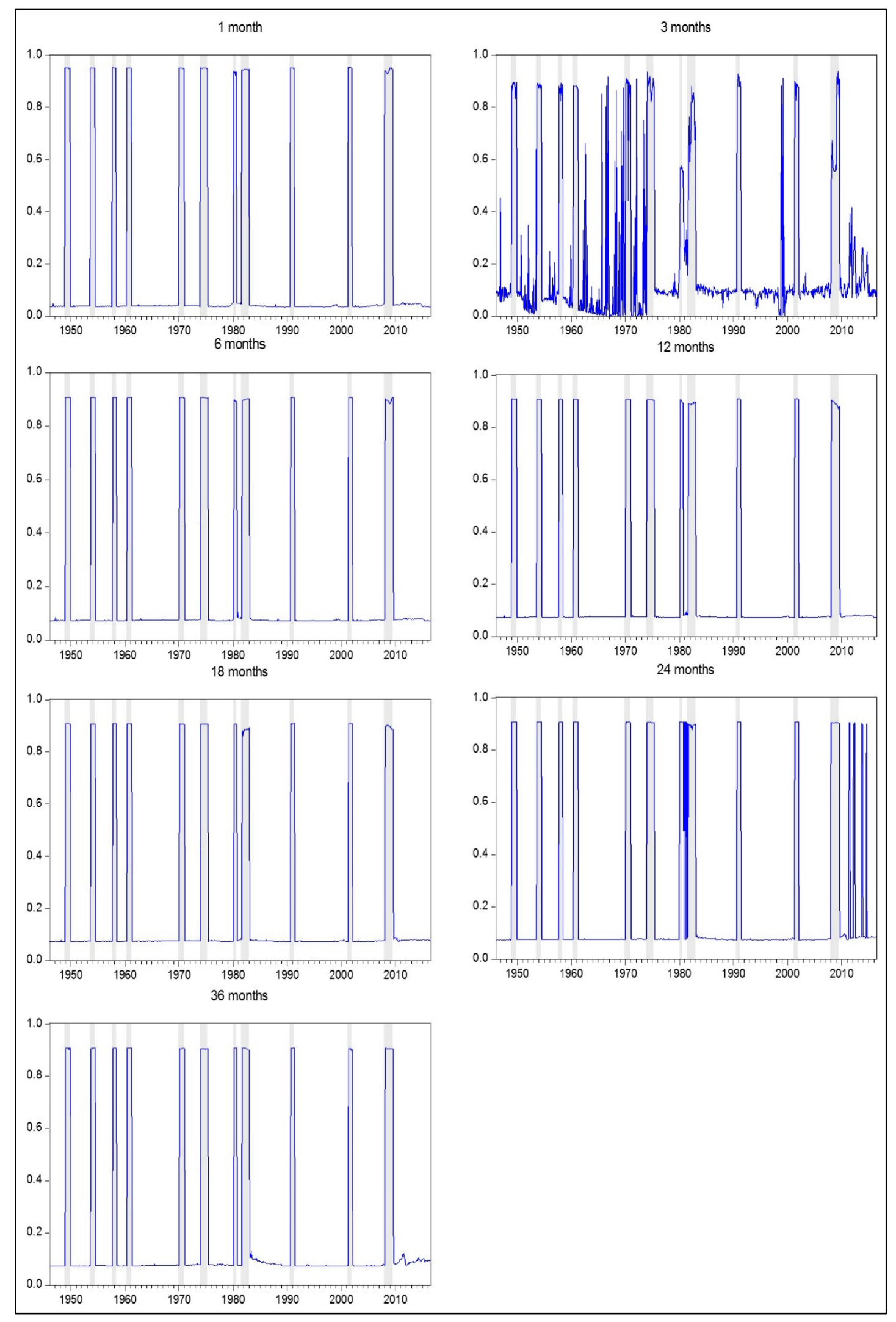

Figure 5: Out-of-sample forecasted probabilities of the AR SVM-RBF models. Grey areas denote NBER recessions. 